\title{
DIFERENTES APRENDIZAGENS: OS DESAFIOS E AVANÇOS DA INCLUSÃO TECNOLÓGICA EM AUDIODESCRIÇÃO COMO RECURSO METODOLÓGICO APLICADO AO ENSINO DE GEOGRAFIA
}

\author{
Different learning: the challenges and advances of inclusion technology in audiodescrição as \\ metodológico resources applied to geography education
}

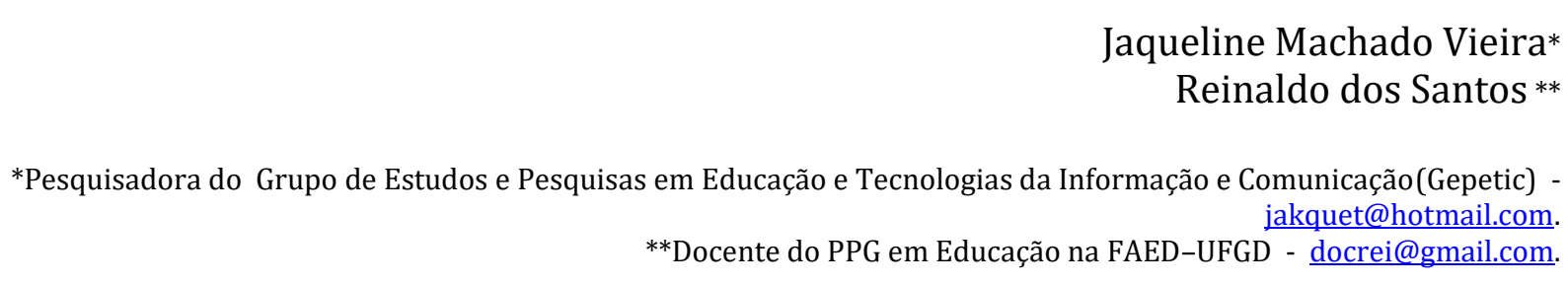

Recebido em 14/08/2018. Aceito para publicação em 25/08/2018.

Versão online publicada em 20/11/2018 (http://seer.ufrgs.br/paraonde)

\begin{abstract}
Resumo:
A proposta do artigo é entender como a Tecnologia em Audiodescrição pode contribuir, de fato, em sala de aula para educandos com deficiência visual, parcial ou total. Buscaremos refletir e reorganizar nossas ideias diante dessas tecnologias que podem beneficiar como metodologias de ensino-aprendizagem e trazer grandes desafios para os docentes da geografia que estão frente a atual conjuntura escolar da nossa sociedade.
\end{abstract}

Palavras-chave: Tecnologias em audiodescrição, deficientes visuais, espaço geográfico

\begin{abstract}
:
The purpose of the articule is to understand how the Technology in Audiodescription can contribute, in fact, in the geographic space of the classroom for students with visual, partial or total deficiency. We will seek reflect and reorganize our ideas regarding these technologies that can benefit as teaching-learning methodologies and bring great challenges to the teachers of geography that are facing the current school situation of our society.
\end{abstract}

Key-words: Technologies in audiodescription, visually impaired, geographic space

\section{Introdução}

Este artigo visa debater sobre a inclusão social, educacional e cultural das pessoas com deficiência visual, especificamente, no que se refere à chegada recente das tecnologias de audiodescrição utilizada como recurso pedagógico inclusivo no cotidiano escolar.

Todavia, para isso, esses recursos devem ser pensados e desenvolvidos para atender as necessidades específicas das diferentes deficiências, e não somente os educandos com deficiência visual com vistas ao bem-estar e participação social dos sujeitos. As tecnologias podem ser um fator de atenuação do processo de exclusão ou ainda de acentuação desse processo, dependendo da forma como são disseminadas e de como as pessoas podem ter acesso a elas. (VIEIRA, 2015)

Nos últimos anos, as discussões sobre inclusão escolar e social dessas pessoas, por meio das produções acadêmicas, têm suscitado questões importantes para o fortalecimento de programas, ações e políticas públicas que assegurem o acesso a formas diferenciadas de ensino-aprendizagem e do desenvolvimento de linguagens alternativas e de acesso aos meios de comunicação, cultura e informação. 
A pesquisa teórica proposta neste artigo, apresenta-se como relevante ao fato de que os educadores devem conhecer e ter informações elementares sobre o que é a audiodescrição; estejam empoderados (pela informação) para reivindicar mais recursos e oportunidades de acessibilidade por meio da audiodescrição, conforme suas demandas cotidianas de cidadania e sobretudo no ambiente escolar; apreendam princípios básicos para fazer audiodescrição para demandantes no cotidiano; transponha barreiras de acessibilidade no que se refere à interação estética com a espacialidade e eventualidade da vivência cotidiana, tendo acesso aos recursos em audiodescrições; esteja inclinado a aprender mais sobre audiodescrição e a ensinar sobre ela para outros sujeitos;

\section{As Tecnologias em Audiodescrição e o Território Geográfico}

Vivemos em um contexto no qual não conseguimos nos desprender das tecnologias de modo geral, seja nos computadores de mesa, notebooks, net books, tabletes, celulares, redes de telecomunicação, programas midiáticos e softwares, esses produtos existem na maioria dos territórios, facilitando, complementando, dinamizando e atuando nos processos pedagógicos educacionais de forma contínua e atual (MATIAS, 2012).

$\mathrm{O}$ avanço de tecnologias, abre um leque de possibilidades para a melhoria de vida das pessoas com e sem deficiências, por meio dos recursos tecnológicos de acessibilidade. A chamada tecnologia assistiva vem melhorando substancialmente a vida das pessoas que delas fazem uso. Com a audiodescrição como recurso tecnológico (tanto para a técnica dos sujeitos para descrever/narrar diretamente e em tempo real para quem não enxerga, quanto para planejar, gravar, editar e disponibilizar objetos comunicacionais em áudio) pensamos não ser diferente.

No entanto, percebemos que, para as interações necessárias, falta para os sujeitos, informação e preparação para o seu uso pleno e autônomo, o que parece comprometer, substancialmente, a interação e utilização desses recursos, constrangendo o acesso e a compreensão daquilo que é vivenciado na mídia e nos espaços públicos, restringindo sua autonomia e limitando sua inclusão social.

As redes tecnológicas do meio técnico-científico-informacional, muito vêm a contribuir na modificação dos territórios, com vários formatos e de diversas maneiras, toda a estrutura de redes informacional e comunicacional podem trazer aspectos impactantes no cotidiano das pessoas e seus territórios. Conforme afirma o autor Milton Santos:

O trabalho se torna cada vez mais trabalho científico e se dá também, em paralelo, a uma informatização do território. Pode-se dizer, mesmo, que o território se informatiza mais, e mais depressa, que a economia ou que a sociedade. Sem dúvida, tudo se informatiza, mas no território esse fenômeno é ainda mais marcante na medida em que o trato do território supõe o uso da informação, que está presente também nos objetos. (SANTOS, 1997, p.70).

Para o autor fica evidente que é no território que se finda e se renova as informações produzidas num determinado tempo e espaço, por isso, devemos levar em conta essa interconexão das informações possibilitadas pelas tecnologias e quais são as condições de seu uso nas formas pedagógicas em sala de aula.

Adentremos na reflexão de que as tecnologias atualmente estão dispersas e interconectadas, porém é preciso um processo de interação entre os sujeitos e as tecnologias para que os educadores consigam manipular e adentrar as redes de comunicação e informação, sobretudo, no que diz respeito às práticas metodológicas e pedagógicas.

Dentre estas tecnologias, a Tecnologia Assistiva ${ }^{1}$ de audiodescrição consiste na transformação

${ }^{1}$ A respeito da Tecnologia Assistiva, no Brasil, o Comitê de Ajudas Técnicas (CAT), instituído pela portaria nº142, de 16 de novembro de 2006 propõe o 
de imagens em palavras para que informações-chave transmitidas visualmente não passem despercebidas e possam também ser acessadas por pessoas com deficiência visual (DV) total, parcial ou com baixa visão. 0 recurso, cujo objetivo é tornar os mais variados tipos de materiais audiovisuais (peças de teatro, filmes, programas de TV, espetáculos de dança, fotografias, mapas, e diversos tipos de imagens e paisagens etc.) acessíveis a pessoas com deficiência visual (FRANCO; SILVA, 2010).

Compreendemos que a audiodescrição é uma necessidade básica as pessoas com Deficiência visual, enquanto direito de acessibilidade igualitária a todo esse público. 0 Brasil dá seus primeiros passos e somente nos grandes centros e capitais é possível encontrar eventos audiodescritos, bem como, ainda é irrisória a quantidade de produtos disponíveis no mercado nacional com este recurso (SANT'ANNA, 2010).

A autora e audiodescritora Lívia Motta (2008) nos remete a refletir que o recurso das tecnologias em audiodescrição, atendem também às necessidades de pessoas com dislexia, deficiência intelectual, deficientes visuais e também os idosos. 0 recurso tecnológico em audiodescrição é um instrumento que contribui e capacita para a inclusão cultural, social e educacional fazendo com que as pessoas que utilizam esses recursos, sejam pessoas críticas, e para o campo das pessoas com deficiência visual, preparando-as para o exercício de domínio do espaço geográfico, suas paisagens, orientações e localizações.

Dizemos que é um recurso tecnológico, que por meio da audição, terá vista sua utilização tanto para a técnica dos sujeitos para descrever/narrar diretamente e em tempo real para quem não enxerga, quanto para planejar, gravar, editar e disponibilizar objetos comunicacionais em áudio. No entanto, percebemos que, para as interações necessárias, falta para os sujeitos, informação e preparação para o seu uso pleno e autônomo, o que parece comprometer, substancialmente, a interação e utilização desses recursos, constrangendo o acesso e a compreensão daquilo que é vivenciado na mídia e nos espaços públicos, restringindo sua autonomia e limitando sua inclusão social. (VIEIRA, 2015).

Nesse sentido, fizemos aqui uma reflexão teórica e discorremos sobre a junção do recurso em audiodescrição para com o ensino de geografia nas práticas pedagógicas e isso vai abrir inúmeras reflexões e possibilidades de inclusão educacional aos sujeitos, sobretudo, em nosso caso, com deficiência visual.

\subsection{Ensino de Geografia nas Práticas Educacionais}

Ao pensarmos, então, o ensino de geografia nas práticas educacionais em sala de aula com os educandos deficientes visuais, elencamos como categoria de estudo o espaço. Entendemos que, juntamente com a tecnologia educacional em audiodescrição, se faz necessário intercalar todas as informações contidas a partir daquilo que o educando com Deficiência Visual já possui construído, por meio da representação do seu mundo vivido, e também conforme sua alfabetização. Fazemos, então, essa junção com alguns aspectos relevantes das tecnologias e o ensino de geografia. Sendo assim, os autores do ensino de geografia, Callai e Callai $(2003$, p.69), nos explica qual é a verdadeira natureza do espaço, dinâmica, e não estática, como foi concebida outrora na geografia tradicional:

Os homens vivem num espaço, atuam-se nele, ocupam lugares. Esse espaço comumente é visto como algo estático, pronto e acabado. Tem uma aparência. Mas é resultado de uma

seguinte conceito para a tecnologia assistiva: "Tecnologia Assistiva é uma área do conhecimento, de característica interdisciplinar, que engloba produtos, recursos, metodologias, estratégias, práticas e serviços que objetivam promover a funcionalidade, relacionada à atividade e participação de pessoas com deficiência, incapacidades ou mobilidade reduzida, visando sua autonomia, independência, qualidade de vida e inclusão social". (BRASIL, 2014, não paginado) 
dinâmica, é cheio de historicidade. A aparência é o resultado, num determinado momento, de coisas que acontecem. É a expressão de um processo, portanto há dinâmica no arranjo. Só na aparência ele é estático, pois este está constantemente sendo construído. E, conhecer o espaço, entendê-lo, é observar está dinâmica e percebê-lo como resultado, mais de que aceitá-lo como definitivo e acabado. Em sendo estático, caberia apenas adaptar-se a ele, ajustar-se para poder viver. E esta era a premissa dos estudos sociais - ajustar ao meio em que vive.

Percebemos que a necessidade de se comunicar é um direito básico voltado ao ser humano, e assim pode se dar de diversas maneiras, seja pela forma oral, por gestos, ou pela audiodescrição que vai, portanto, transformar as imagens do espaço geográfico em palavras. Com tecnologia em audiodescrição, entramos na linguagem da representação do mundo para com a pessoa com Deficiência Visual, que começa a moldar e formatar suas palavras. Podemos compreender o quanto é necessário à junção da realidade do espaço vivido do educando com a comunicação que a audiodescrição lhe proporciona. Se tornando sua ferramenta de comunicação a partir do seu olhar de mundo no espaço, na qual, habita. Tendo em vista que olhar o mundo, não é apenas enxerga-lo, pois, cada indivíduo tem uma visão sobre o mundo a partir da ideologia que acredita. Como afirma Fantin apud Sant'Anna (2010, p.157):

No entanto, olhar o mundo não envolve só a visão, pois o olhar é fruto de uma individualidade que é parte de uma história pessoal e única vivida em determinada sociedade, com determinada cultura, numa determinada época, vinculada a determinado momento específico de vida, que constroem um jeito próprio de ver. Esse repertório individual envolve, além dos conhecimentos específicos, os valores estéticos, filosóficos, éticos e políticos, assim como a ideologia do indivíduo, do grupo ou da classe social à qual pertence. E nesse processo de educação do olhar, aprendemos a olhar o mundo, a natureza, o trabalho e a arte com o olhar do outro, pela mediação de outros jeitos de olhar. Esses olhares podem ser desinteressados, interpretativos ou criativos.

Contudo, a revolução das tecnologias da informação e comunicação se pauta numa rede multidimensional em seus aspectos culturais, sociais, econômicos e políticos de uma determinada nação envolvendo sujeitos que vão assumir essas redes de forma estratégica e que aperfeiçoará estes instrumentos para a globalização e a descentralização dos territórios (MATIAS, 2012). Dessa maneira, observamos que a tecnologia no campo educacional é algo inerente a realidade dos sujeitos educandos e educadores e ela é responsável por criar essa necessidade de repensarmos "novas" práticas pedagógicas mais dinâmicas e atuais. Segundo Dalben e Castro apud Oliveira (2013, p.49).

[...] afirmam que os impactos provocados por essas tecnologias refletem na educação, possibilitando a propagação do conhecimento por meio de diálogos constantes para a sua inserção nas escolas. Isso denota, portanto, que a relação escola/currículo/tecnologia não pode ser pensada de forma dissociada. A escola deve propiciar diferentes discursividades entre os profissionais da educação a fim de que um novo currículo esteja conectado não somente aos aspectos sociais, culturais, político e escolares, como também ao tecnológico.

Por isso, tratamos aqui sobre as tecnologias assistivas de audiodescrição como meio tecnológico e pedagógico educacional diferenciado para os processos educativos que emergem em nossa sociedade. Pois, o profissional educador de diferentes áreas, e os sujeitos educandos não devem ficar "de fora" em nossa sociedade em rede onde o conhecimento provindo da tecnologia de audiodescrição que vem ganhando importância e espaço. 


\subsection{Espaço Geográfico da Escola}

$\mathrm{Na}$ atualidade muitos professores que precisam utilizar os recursos da tecnologia em suas práticas pedagógicas, mas não conseguem operacionaliza-la ou mesmo interagirem com ela, principalmente, pelo fato, de que os aparatos tecnológicos mudam numa intensidade maior do que as possibilidades que o professor tem de incorporar estes novos conhecimentos. Dessa forma, as tecnologias podem avançar no que diz respeito a diversas áreas educacionais, porém é preciso encontrar profissionais capazes de manipular suas técnicas de uso funcional.

A escola deveria ser um espaço importante para se pensar em mudanças sociais, formando pessoas pensantes e críticas, discutindo sobre a superação da dominação capitalista. Pois, é preciso superar as contradições impostas por este sistema vicioso e reprodutor do capital, que exclui, desapropria, segrega, desterritorializa os sujeitos e os oprime demasiadamente. Também, é preciso romper com o individualismo e alienação que divide os sujeitos e impede que os mesmos se vejam inseridos nas péssimas condições de trabalho, até mesmo indignas de sobrevivência, na qual, estão submetidos (FREIRE, 1999).

A emancipação, a ruptura e a transformação social, tendo como um instrumento a educação, são objetivos norteados pelo pensamento marxista. É preciso uma reformulação na educação que estabeleça a coletividade como forma de vida social. Também, a compreensão da divisão da sociedade em classes sociais, contribui na formação crítica dos alunos diante de sua realidade vivida. É este o objetivo de uma educação escolar sob os pressupostos teóricos e metodológicos do materialismo histórico e dialético (GADOTTI, 2000).

Este método na educação nos auxilia a entender a realidade como parte da totalidade em constante movimento de transformação, onde o processo de produção/reprodução socioespacial e territorial se fazem historicamente pelas classes que compõem a sociedade por meio das relações de trabalho entre sociedade e natureza. A precisão dessa ruptura com o modelo que doutrina se faz devido à coisificação/alienação/exploração do ser humano decorrente do modo de produção capitalista e de sua sociedade estratificada. Daí a necessidade de luta por uma sociedade mais justa e igualitária construída a partir dos movimentos sociais e de um projeto de ensino que parta de todas as áreas em união com a educação crítica, pensante emancipatória (FREIRE, 1999; OLIVEIRA, 2007).

Ainda no âmbito teórico, buscamos assumir uma postura investigativa e crítica perante a acessibilidade comunicacional e o papel da escola e da tecnologia na formação e preparação dos jovens para a interação sociocultural com esses recursos, de forma que ultrapasse os limites dos seus muros e contribua para a participação social e inclusiva desses sujeitos.

Para Habermas (2006, p. 61-62), a ação comunicativa se tornar poder comunicativo pela via do direito nas sociedades democráticas. Os conceitos que norteiam seu pensamento são os de que a aprendizagem e a socialização são fatores imprescindíveis tanto para a ação como para o discurso. Essa teoria defende a emancipação e libertação do sujeito por meio de um processo permanente de interação comunicativa com o propósito de construir uma verdade coletivamente elaborada e socialmente aceita.

\section{Metodologia}

Após as atividades iniciais de pesquisa bibliográfica e documental, de fundamentação teórica, temática, legal e técnica sobre tecnologias, inclusão e tecnologia assistiva, a metodologia da pesquisa maior, prevê a organização do trabalho simultâneo em duas frentes temáticas, distintas, 
mas articuladas, sendo a primeira já debatida nesse artigo em formato teórico na qual foram feitas a Pesquisa bibliográfica: com leituras e sistematização de obras teóricas, metodológicas e temáticas sobre educação, inclusão, deficiência visual, espaço geográfico, tecnologia e audiodescrição; posteriormente, já adentrando na segunda fase do mestrado, vamos desdobrar na prática em sala de aula, levando portanto a audiodescrição juntamente com o ensino de geografia para algumas escolas públicas, ainda a serem definidas da cidade de Dourados $\mathrm{MS}^{2}$, onde a pesquisa de mestrado da autora está em andamento.

\section{Protocolo de Ação em sala de aula com os sujeitos professores}

Realizaremos uma produção em audiodescrição: com planejamento, padronização, testes e validações de audiodescrições de ambientes e espaços geográficos com alunos e professores da educação básica da cidade de Dourados MS, no ensino de geografia; A ação pedagógica, visará o diagnóstico, elaboração, desenvolvimento e avaliação de um Plano de Intervenção Pedagógica para ensino e difusão de audiodescrição entre professores da educação básica, deficientes visuais e videntes; e a expectativa se encontrará nos resultados e produtos dessa pesquisa que irá também fazer um levantamento desses materiais pedagógicos para difusão dos resultados dessa pesquisa, procedimentos desenvolvidos e estratégias sobre o tema, juntamente com os professores, salas de aula de atendimento educacional especializado, estudantes de licenciatura, geógrafos, entidades representativas de cegos e pessoas com Deficiência Visual da cidade de Dourados MS.

\section{Considerações Finais}

A doutrina materialista de que os homens são produto das circunstâncias e da educação, que homens diferentes são, portanto, produto de outras circunstâncias e de uma educação diferente, esquece que as circunstâncias são, na verdade, modificadas pelos homens e que o próprio educador deve ser educado. [...]. (MARX, 2016b, p. 1).

Marx nos deixa o legado da reflexão de que tanto a educação quanto as tecnologias são produtos de relações sociais construídas historicamente no interior da sociedade de classes e, portanto, as mudanças sociais implicam em mudanças educacionais e vice-versa.

Os conceitos de ideologia e de classes sociais nos auxiliam a entender melhor o funcionamento da sociedade e suas implicações no que concerne à educação e a tecnologia. Sendo que, dadas às condições de exploração, dominação e opressão inerentes ao modo de produção capitalista, faz-se necessário que a educação e a tecnologia auxiliem na superação das contradições e na consequente emancipação humana.

As redes tecnológicas do meio técnico-científico-informacional (SANTOS,1997) muito vêm a contribuir na construção dos territórios, independentemente de seus tamanhos e formas, todas as estruturas informacionais podem trazer aspectos impactantes nos processos educativos, pois nos territórios escolares está ocorrendo uma des-re-territorização (HAESBAERT, 2006) com a chegada dessas novas redes tecnológicas no campo educacional.

0 território escolar está sendo marcado pelas novas e mais diversas informações e tecnologias de forma constante e dialética. Neste processo os sujeitos envolvidos, alunos, professores e pais, estabelecem relações/interacionais (ELIAS,1993) em diferentes níveis escalares, ultrapassando a esfera local. Para que possa se garantir está adaptação e reformulação do ambiente escolar a esta nova realidade global, é necessário um esforço para que estes sujeitos estejam instrumentalizados para lidar com esses mecanismos tecnológicos.

${ }^{2}$ Atualmente, é a segunda maior cidade do Estado do Mato Grosso do Sul, em população, com 196.068 habitantes, segundo o censo do IBGE (2010). Sua rede urbana está ligada a Campo Grande, e por intermédio dela, a grande metrópole nacional São Paulo. Suas articulações com a cidades vizinhas e menores são constituídas pelos serviços e comércios que desempenham papéis importantes beneficiando a cidade de Dourados na condição de cidade Média. 
Os processos, no geral, envolvem a aprendizagem da tecnologia que condiz com a sociedade em uma determinante época. Tudo isso faz com que os indivíduos conquistem mobilidade, flexibilidade e acesso a informação que a tecnologia o proporciona. Porém, por contradição, quanto mais coisificamos as relações, nos tornamos individualistas, levando a reflexão de que apesar de ás máquinas serem objetos fabricados pelo ser humano, também podemos ter nossas atitudes condicionadas por estas máquinas tecnológicas.

Contudo isso, é possível o desencadeamento de uma educação que provoque constantes reflexões acerca dos avanços e desafios do papel das tecnologias no alargamento das relações sociais entre os indivíduos. Portanto, concluímos que os recursos tecnológicos, aqui debatidos, possam permitir as pessoas, com ou sem deficiências, entenderem e se identificarem em seu território e espaço geográfico.

É no território que se finda e se renova as informações produzidas num determinado tempo e espaço, por isso, devemos levar em conta essa interconexão das informações possibilitadas pelas tecnologias e quais são a condição de seu uso de forma metodológica na sala de aula. Dessa maneira, a tecnologia no campo educacional é algo inerente à realidade dos sujeitos educandos e educadores e ela é responsável por criar essa necessidade de "novas" práticas pedagógicas mais dinâmicas e atuais.

\section{Referências}

BRASIL. Tecnologia assistiva. ATA VII. Comitê de Ajudas Técnicas (CAT). Coordenadoria Nacional para Integração da Pessoa Portadora de Deficiência (CORDE). Secretaria Especial dos Direitos Humanos. Disponível em: . Acesso em: 29 jun. 2014.

CALLAI, Helena Copetti; CALLAI, Jaeme Luiz. Grupo, espaço e tempo nas séries iniciais. In: CASTROGIOVANNI, Antônio Carlos et al. (Orgs.). Geografia em sala de aula: práticas e reflexões. 4. ed. Porto Alegre: UFRGS; Porto Alegre: AGB - seção Porto Alegre, 2003. p. 65- 75.

ELIAS, Norbert. $O$ processo civilizador: formação do Estado e Civilização. vol. 2, Rio de Janeiro: Jorge Zahar editor, 1993. vol. 2.

FRANCO, Eliana Paes Cardoso; SILVA, Emanuela Cristina Correa Carvalho da. Audiodescrição: breve passeio histórico. In: MOTTA, Lívia Maria Villela de Mello, FILHO, Paulo Romeu (Orgs.). Audiodescrição: transformando imagens em palavras. São Paulo: Secretaria dos Direitos da Pessoa com Deficiência do Estado de São Paulo, 2010. p. 23-42.

FREIRE, Paulo. Pedagogia da autonomia: saberes necessários à pratica educativa. 12. ed. São Paulo: Paz e Terra, 1999.

GADOTTI, Moacir. Concepção dialética da educação: um estudo introdutório. 11. ed. São Paulo: Cortez, 2000.

HABERMAS, Jürgen. Direito e democracia: entre facticidade e validade. Trad. Flávio Beno Siebeneichler. Rio de Janeiro: Tempo Brasileiro,1997. v. 1.

HAESBAERT, Rogério. O mito da desterritorialização: do "fim dos terrritórios" a multiterritorialidade. 2. ed. Rio de Janeiro: Bertrand Brasil, 2006.

MARX, Karl; ENGELS, Friedrich. A ideologia alemã. Tradução de Luis Cláudio de Castro e Costa. São Paulo: Martins Fontes, 2001. (Coleção Clássicos - Filosofia/ Ciências Sociais).

MARX, Karl; ENGELS, Friedrich. O manifesto comunista. Disponível em: . Acesso em: 01 ago. 2016

MATIAS, Vandeir Robson da Silva. Ciência, tecnologia e sociedade: 0 lugar do ensino de geografia, Revista Educação e Tecnologia, Belo Horizonte, vol. 17 n. 3 p. 56 - 66, set. /dez. 2012.

MOTTA, Lívia Maria V. Mello. Audiodescrição: recurso de acessibilidade para a inclusão cultural das 
pessoas com deficiência visual. 2008.

OLIVEIRA, Maria Rita N. S. Um grande desafio na integração das tecnologias da informação e comunicação na formação docente. In: TAVARES, Rosilene Orta; GOMES, Suzana dos Santos. (Org.). Sociedade, educação e redes: desafios à formação crítica. Araraquara - SP: Junqueira Marin, 2014.

SANT'ANNA, Laércio. A Importância da audiodescrição na comunicação das pessoas com deficiência. In: MOTTA, Lívia Maria Villela de Mello; FILHO, Paulo Romeu (Orgs.). Audiodescrição: transformando imagens em palavras. São Paulo: Secretaria dos Direitos da Pessoa com Deficiência do Estado de São Paulo, 2010. p. 151-158.

SANTOS, Milton. A natureza do espaço: técnica e tempo, razão e emoção. São Paulo: Hucitec, 1997.

VIEIRA, Jaqueline Machado. Geografias para além dos olhos: a linguagem geográfica dos deficientes visuais - estudo a partir da Escola Prof. Faradei Bôscoli. 72 f. Monografia (Monografia em Geografia) - Universidade Estadual Paulista, Faculdade de Ciências e Tecnologia, Presidente Prudente SP: [s.n], 2015.

VIEIRA, Jaqueline Machado. Para ver os Mapas com Palavras: Audiodescrição como Recurso Pedagógico no Ensino de Geografia para a Inclusão de Pessoas com Deficiência Visual. 200 f. Dissertação (Mestrado em Educação) - Faculdade de Educação, Universidade Federal da Grande Dourados. Dourados MS, 2018. 